\title{
ALGUNOS DATOS PARA LA HISTORIA DEL RECIÉN RIOPLATENSE
}

JOSÉ LUIS RAMÍREZ LUENGO

Universidad de Jaén

1. Es de sobra conocido el peculiar empleo del adverbio recién que se da en el español de América, caracterizado por una ampliación de sus posibilidades de aparición respecto a los usos habituales en España: en efecto, ejemplos del estilo de como si recién te conociera demuestran que, junto a su empleo como modificador de participios — presente también en las variedades peninsulares del español-, en las americanas este elemento ha incrementado sus contextos de empleo, y puede, por tanto, funcionar de forma autónoma con un claro valor temporal ${ }^{1}$.

Este aumento de sus posibilidades de utilización conlleva también una diversificación de sus valores y matices significativos, de manera que, junto a su significado de 'reciente', el adverbio recién presenta, en las regiones de América donde los mencionados usos innovadores se registran, otros significados de carácter temporal que Kany ${ }^{2}$ sintetiza en tres: 1) 'ahora mismo, hace poco tiempo’; 2) 'sólo, sólo entonces, no antes' — señalado también por Kovacci ${ }^{3}$ —; y 3) 'apenas, tan pronto como'; apunta, además, el mismo Kany ${ }^{4}$ que el segundo significado suele ser el más habitual, si bien en ocasiones resulta complicado distinguir el matiz predominante entre las diferentes posibilidades que este recién puede presentar ${ }^{5}$.

\footnotetext{
${ }^{1}$ Alonso Zamora Vicente, Dialectología Española, Madrid, Gredos, 1966, pág. 438; Rafael Lapesa, Historia de la Lengua Española, Madrid, Gredos, 1981, pág. 593.

${ }^{2}$ Charles E. Kany, Sintaxis Hispanoamericana, Madrid, Gredos, 1969, pág. 379.

${ }^{3}$ Ofelia Kovacci, «El adverbio», Gramática Descriptiva de la Lengua Española I, I. Bosque y V. Demonte, dirs., Madrid, Espasa-Calpe, 1999, 705-86, pág. 775.

${ }^{4}$ Charles E. Kany, op. cit., pág. 379.

5 Téngase en cuenta que el matiz significativo deriva en muchas ocasiones del contexto sintáctico en que aparece este elemento, de manera que su uso como modificador verbal (por ejemplo, recién salió) impone el valor uno señalado por Charles E. Kany, op. cit., pág. 379, 'ahora mismo, hace poco tiempo', mientras que su empleo como introductor de un complemento tem-
} 
En cuanto a su distribución diatópica, es de nuevo Kany ${ }^{6}$ quien indica lo incorrecto de considerar estos usos como argentinismos, dado que, si bien es verdad que resultan muy frecuentes en el área rioplatense, lo cierto es que aparecen también con cierta frecuencia en zonas como Chile, Bolivia, Perú y Ecuador, así como de manera más escasa en otras regiones del continente, tales como Colombia, los llanos de Venezuela, Costa Rica, Guatemala, México ${ }^{7}$ o la República Dominicana; en el caso concreto del Río de la Plata, Moreno de Alba ${ }^{8}$ certifica la presencia de los usos innovadores a ambas orillas, Argentina y Uruguay, mientras que Vidal de Battini ${ }^{9}$ precisa su extensión sociolingüísti$\mathrm{ca}$, al indicar su carácter general en el habla de todos los estratos sociales e incluso en la literatura ${ }^{10}$.

Por lo que se refiere a los orígenes históricos de estos usos, se debe indicar que parecen ser posteriores, al menos, al siglo XVI, dado que Keniston ${ }^{11}$ no los registra en su estudio de la morfosintaxis del español de esta centuria. De hecho, es Cuervo ${ }^{12}$ quien va a citar algunos ejemplos, ya del siglo XVII, que parecen presagiar los usos americanos actuales, y que se caracterizan por presentar recién como modificador de un elemento distinto al participio, en concreto

poral (al estilo de recién entonces salió) parece favorecer el valor tres de Charles E. Kany, op. cit., pág. 379, 'apenas, tan pronto como', y muy especialmente el número dos, 'sólo, sólo entonces, no antes', señalado tanto por este autor como por Ofelia Kovacci, op. cit., pág. 775.

${ }^{6}$ Charles E. Kany, op. cit., págs. 379-381.

${ }^{7}$ Según indican Fulvia Colombo y María Ángeles Soler, «¿Errores morfosintácticos en el español escrito?», Cambio lingüístico y normatividad, F. Colombo y M. A. Soler, coords., México DF, Universidad Nacional Autónoma de México, 2003, 171-178, pág. 174, en el caso concreto de México los usos innovadores de recién no sólo son muy habituales en hablantes del nivel sociocultural alto, sino que incluso son reconocidos como correctos por éstos, lo que, en su opinión, demuestra la instauración de una nueva norma, diferente a la académica, en el español estándar de esta zona.

${ }^{8}$ José G. Moreno de Alba, El español en América, México DF, Fondo de Cultural Económica, 1993, pág. 193.

9 Berta E. Vidal de Battini, El español de la Argentina, Buenos Aires, Consejo Nacional de Educación, 1966, págs. 191-2.

${ }^{10}$ Este empleo general de recién sin participio no es algo propio exclusivamente de la zona rioplatense, sino que se produce en todas las variedades del español donde estos usos existen, según observa Charles E. Kany («American Spanish recién», Hispanic Review, 13, 1945, 169-73, pág. 171): "it has persisted in certain regions not only among the untutored but also among the cultured classes, not only in familiar speech but also in elevated literary style"; de hecho, es la amplia aceptación de estos usos en América lo que lleva a Leonardo Gómez Torrego (Nuevo Manual del Español Correcto II, Madrid, Arco Libros, 2004, pág. 581) a calificarlos de "fenómeno de la norma americana que debe considerarse legítimo".

${ }^{11}$ Howard Keniston, The syntax of Castilian Prose. The sixteenth Century, Chicago, The University of Chicago Press, 1937, pág. 593.

12 Rufino J. Cuervo, «Notas a la gramática de la lengua castellana de D. Andrés Bello», en Andrés Bello, Gramática de la Lengua Castellana II, Madrid, Arco Libros, 1988, 785-974 (ed. de R. Trujillo), págs. 882-883. 
un adjetivo o sustantivo: recién libres en Cervantes, recién heredero en Estebanillo González, o recién ministro en Alarcón ${ }^{13}$; en el caso concreto de América, ya a lo largo de los siglos XVII y XVIII es posible registrar, junto a apariciones como las anteriores, algunos empleos coincidentes con los que actualmente se dan en el nuevo mundo ${ }^{14}$, según ponen de manifiesto los siguientes ejemplos (ejemplos 1 y $2^{15}$ ):

1. Ahora recién profesó cuando se fundó, y se mudó de un sitio corto y breve que tenían junto al convento de San Augustín (Chile, 1605)

2. Recién el año pasado el Padre Nicolás bolbió á amistar con intentos de poblarlos (Ecuador, 1735)

Más allá de los casos inmediatamente aducidos, la presencia más o menos general de estos usos en algunas regiones de América queda más que demostrada por la denuncia explícita de ellos que lleva a cabo Bello, tanto en sus Advertencias sobre el uso de la lengua castellana de $1833^{16}$, como posteriormente en su Gramática: «Es una corrupción emplear esta apócope con verbos, como hacen algunos diciendo v. gr. recién habíamos llegado; recién estaba yo despierto» ${ }^{17}$. Es evidente, por tanto, que estos usos presentan cierta frecuencia en el español americano del siglo XIX, en el que muy probablemente se da ya una situación semejante a la que existe hoy en día en las diversas zonas del continente donde este fenómeno se produce.

Así pues, a la luz de lo expuesto más arriba se hace del todo evidente que los datos conocidos hasta el momento sobre la evolución histórica de recién en América no pasan de ser escasos y muy parciales, por lo que es aún mucho lo que queda por analizar a este respecto; de este modo, es preciso «llevar a cabo estudios que expliquen en qué momento y por qué motivo sufre recién las modificaciones ya indicadas» ${ }^{18}$, a fin de establecer con cierta seguridad las causas

${ }^{13}$ Nótese, con todo, que tales casos no son aún semejantes a los que hoy en día se descubren en América, en los que recién aparece de forma autónoma (salió recién), o sirve para introducir un complemento de valor temporal (recién ahora lo sé; recién hace dos semanas terminaron).

14 José L. Ramírez Luengo, Breve historia del español de América, Madrid, Arco Libros, 2007, pág. 68.

15 Ambos casos aparecen citados en José L. Ramírez Luengo, op. cit., pág. 68, y se han tomado de CORDE; en concreto, el ejemplo chileno se descubre en la Descripción breve de toda la tierra del Perú, Tucumán, Río de la Plata y Chile, de Fray Reginaldo Lizárraga (Madrid Manuel Serrano y Sanz, Bailly-Baillière, 1909); el ecuatoriano, en la anónima Relación de la misión apostólica en la provincia de Quito de la Compañía de Jesús (Madrid, Librería de Victoriano Suárez, 1904).

16 Andrés Bello, Advertencias sobre el uso de la lengua castellana, La Plata, Ministerio de Educación de la Provincia de Buenos Aires, 1956, pág. 33.

17 Andrés Bello, Gramática de la Lengua Castellana, op. cit., pág. 331.

18 José L. Ramírez Luengo, op. cit., pág. 69. 
y la cronología de unos empleos tan característicos de determinadas variedades del español americano.

2. En esta línea, el presente trabajo pretende llevar a cabo un estudio sobre la historia de la forma recién en el español rioplatense, con el propósito de establecer en qué momento se producen las transformaciones mencionadas más arriba y —en la medida de lo posible- describir el proceso de cambio y las causas que originan estos peculiares empleos característicos hoy de la República Argentina y el Uruguay.

Con esta intención, se ha analizado el uso de este elemento en el banco de datos CORDE de la Real Academia Española ${ }^{19}$, en concreto en los fondos correspondientes a Argentina y Uruguay que se datan entre 1550 y 1900, fechas tope de este estudio; además, este corpus se ha completado con los textos uruguayos y argentinos que se pueden encontrar en los Documentos para la historia lingüística de Hispanoamérica (siglos XVI-XVIII) publicados por ALFAL - en concreto, en su tercer volumen ${ }^{20}$ - a fin de contar con un número representativo de ejemplos en que basar el análisis.

Por lo que se refiere a la recolección de los datos - y dadas las características de CORDE - , se ha llevado a cabo una búsqueda exhaustiva delimitada geográficamente a Argentina y Uruguay ${ }^{21}$, en la que se han considerado todas las posibles grafías con que recién podría aparecer en los textos; en concreto, las variantes investigadas han sido las siguientes: recien-rrecien, recyen-rrecyen, rezien-rrezien, rezyen-rrezyen, reçien-rreçien, reçyen-rreçyen, con y sin acentuación gráfica, así como las posibles formas seseantes (resien-rresien, resyen-rresyen, ressien-rressien, ressyen-rressyen), también con y sin tilde.

Es necesario indicar, sin embargo, que el manejo de toda esta documentación no ha ofrecido el elevado número de ocurrencias que podía suponerse, ya que éstas se reducen a un total de 223, 170 casos en Argentina ${ }^{22}$ y 53 en Uru-

${ }^{19}$ Se puede consultar en la página web de esta institución: www.rae.es; todas las búsquedas se llevaron a cabo los días 22 y 23 de noviembre de 2006.

${ }^{20}$ Elena M. Rojas, Documentos para la Historia Lingüística de Hispanoamérica III, Tucumán, Universidad Nacional de Tucumán, 2001. Este volumen está publicado en formato digital, y se puede consultar también en internet en la siguiente dirección: http://pizarro.fll.urv.es/ proyecto.htm.

21 Conviene indicar, con todo, que se han utilizado también los datos que ofrece CORDE sobre otras áreas geográficas para la presentación de ejemplos que ofrezcan más luz sobre la historia de recién o corroboren lo expuesto en estas páginas, si bien tales búsquedas en ningún caso han sido detalladas o exhaustivas como en el caso del Río de la Plata.

22 Aunque la práctica totalidad de los ejemplos argentinos provienen del área del Río de la Plata (a grandes trazos, las provincias de Buenos Aires y Santa Fe), es necesario indicar que algunos de los que se encuentran en ALFAL tienen su origen en otras regiones del país, en concreto Tucumán y Jujuy; con todo, habida cuenta de que estos casos son únicamente cinco y siempre 
guay, con una concentración muy significativa de ejemplos en el siglo XIX —en concreto, 199 de los 223, esto es, el 89'23\%- y una presencia muy reducida en centurias anteriores: 22 casos en el siglo XVIII y dos únicas apariciones en el siglo XVII. Es del todo evidente, por tanto, que los datos aquí aportados constituyen únicamente una primera aproximación a la historia de recién en el Río de la Plata, que se deberá completar con posteriores aportes en los que las diferentes épocas - muy especialmente, los siglos XVII y XVIII- estén mejor representadas.

3. Tal y como se acaba de indicar, el análisis detallado del corpus arroja un total de 223 casos de recién, en los que aparecen tanto ejemplos de los usos tradicionales como de lo que se ha dado en llamar usos innovadores o propiamente americanos, en los que este elemento funciona de forma autónoma o se acompaña de otro tipo de complemento diferente al participio; en concreto, una primera división entre empleos con y sin participio muestra un equilibrio muy notable entre ambas posibilidades, que se reparten casi al 50\%: 113 casos participiales frente a 110 con otros elementos, esto es, un 50'67\% y un 49'32\% respectivamente.

Ahora bien, una aproximación más detallada que haga hincapié en el desarrollo cronológico de estos empleos, pone de manifiesto una distribución mucho menos proporcionada entre ambos tipos de usos, relacionada directamente con el siglo que se tenga en cuenta, tal y como se descubre en la siguiente tabla (tabla 1):

TABLA 1

Uso de recién en el Río de la Plata (Siglos XVII-XIX)

\begin{tabular}{|c|l|c|c|}
\hline Uso & \multicolumn{1}{|c|}{ Siglo XVII } & Siglo XVIII & \multicolumn{1}{c|}{ Siglo XIX } \\
\hline - Con Participio & $2(100 \%)$ & $22(100 \%)$ & $89(44 ’ 72 \%)$ \\
\hline - Sin Participio & $0(0 \%)$ & $0(0 \%)$ & $110\left(55^{\prime} 27 \%\right)$ \\
\hline TOTAL & $2(100 \%)$ & $22(100 \%)$ & $199(100 \%)$ \\
\hline
\end{tabular}

De este modo, los datos anteriores ofrecen una muestra clara del desarrollo de los usos participiales y no participiales de recién en la historia del español rioplatense, y evidencian la importancia que el siglo XIX adquiere para la evolución diacrónica de este elemento en la región: en efecto, mientras que en los siglos XVII y XVIII no se registra ni un solo ejemplo de los usos innovadores

presentan la construcción recién + participio, se ha optado por considerarlos conjuntamente con los datos propiamente rioplatenses. 
propios del español americano actual ${ }^{23}$, el siglo XIX se caracteriza por la presencia de tales empleos, que no sólo aparecen por primera vez en esta centuria $^{24}$, sino que incluso alcanzan un notable porcentaje de utilización, equivalente a un $55 \%$ de todos los casos registrados (ejemplos 1 al 5):

1. Equivoca el temor con la destreza y recién abandona la aspereza (Argentina, 1822-1838)

2. Mirando recién entonces a su alrededor empezó a repartir saludos (Argentina, 1854)

3. Terminados los aprestos, recién anuncié a los que formaban mi comitiva (Argentina, 1870)

4. La frase la hirió, advirtiendo recién entonces que la mano del viejo pescador pesaba (Uruguay, 1886)

5. El fuego debía haber empezado recién (Uruguay, 1892)

Es interesante hacer hincapié, a este respecto, en el hecho de que no sea posible localizar ni un solo ejemplo de estos usos innovadores en los siglos XVII y XVIII, ni en los materiales argentinos ni en los uruguayos: si bien es cierto que, según se apuntó anteriormente, el número de ocurrencias de esta época no es demasiado abundante en el corpus - poco más del $10 \%$ de todos los casos-, la total ausencia de ejemplos obliga a plantearse si esta innovación se extiende por la zona rioplatense ya en el siglo XIX o, en el supuesto de que así no sea, por qué es en este preciso momento cuando comienza a aparecer por escrito $^{25}$.

${ }^{23}$ Lo que en principio parece cuestionar las afirmaciones de Vidal de Battini, op. cit., pág. 192, quien indica que tal uso innovador «viene de la época hispánica».

${ }^{24} \mathrm{Al}$ menos, evidentemente, por primera vez en los materiales que componen el corpus aquí estudiado.

${ }^{25}$ Resulta interesante interrogarse también acerca del proceso que lleva de los primitivos usos peninsulares de recién, exclusivamente seguido de participio, a estos nuevos empleos en los que esta forma aparece de forma autónoma o introduce un complemento mayoritariamente temporal; en principio, es muy probable que el germen de esta transformación — que se encuadra en la tendencia básica del cambio lingüístico «a manipular pragmáticamente, discursivamente, las formas de manera innovadora» (Concepción Company, «¿Qué es un cambio lingüístico?», Cambio lingüístico y normatividad, op. cit., págs. 13-32, pág. 23) - se encuentre en ejemplos como los que localiza Rufino J. Cuervo, op. cit., págs. 882-3, en el siglo XVII: en efecto, en este momento, tal y como documenta el maestro colombiano, recién no sólo aparece acompañado de participios ('Está recién casado con una hermosa mujer', Salas Barbadillo, España, 1614; 'La silla no ha de estar recién henchida, Cárdenas y Angulo, España, 1651), sino también de diferentes adjetivos, categoría funcionalmente equivalente a la primera (entre otros casos, 'Estuvo en un lugar mitad de la jornada, como recién convaleciente', Céspedes y Meneses, España, 1623; 'La Reina Doña Leonor, recién viuda del Rey Don Manuel de Portugal, Fernández de Córdoba, España, 1625).

A partir de aquí, parece darse una ampliación de las posibilidades sintácticas de este elemento, de manera que, por un lado, a partir de su empleo con nombres bicategoriales como viudo, pasa a emplearse con otros sustantivos, probablemente en primer lugar referidos a personas - $\mathrm{el}$ caso de recién ministro señalado por Rufino J. Cuervo, op. cit., pág. 882, en Alarcón, u otros 
Teniendo en cuenta, por tanto, la importancia que el siglo XIX parece tener en la historia del recién rioplatense, es interesante analizar la evolución de los usos participiales y no participiales a lo largo de esta centuria; de acuerdo con los datos del corpus, tal evolución es la siguiente (tabla $2^{26}$ ):

TABLA 2

Uso de recién en el Río de la Plata (Siglo XIX)

\begin{tabular}{|c|c|c|c|}
\hline Uso & $1801-1835$ & $1836-1870$ & $1871-1900$ \\
\hline - Con Participio & $2(40 \%)$ & $56\left(53^{\prime} 85 \%\right)$ & $31\left(344^{\prime} 44 \%\right)$ \\
\hline - Sin Participio & $3(60 \%)$ & $48\left(46^{\prime} 15 \%\right)$ & $59(65 ' 55 \%)$ \\
\hline TOTAL & $5(100 \%)$ & $104(100 \%)$ & $90(100 \%)$ \\
\hline
\end{tabular}

como 'Viviendo yo en él, recién sacerdote' (Lizárraga, Chile, 1605)—, y posteriormente sin tal referencia personal, en unos usos que se pueden considerar el antecedente directo del recién + complemento temporal habitual hoy en América, y cuyo complemento puede ser, efectivamente, un sustantivo (recién esta semana), pero también un adverbio (recién entonces) o un nexus completo (recién hace dos meses).

Por otro lado, los datos de CORDE demuestran que los empleos de recién seguido de participio determinan que este elemento aparezca con cierta frecuencia junto a los tiempos compuestos, muy especialmente en los formados con el auxiliar ser (entre otros muchos casos, 'Vivar es recién venido y querrá entrar descansado', Lope de Vega, España, 1602; 'Como era recién passado el diluuio vniuersal', Vázquez de Espinosa, 1629; 'Era recién venida de Francia', Castillo Solórzano, 1637; 'Eran recién entrados en esta tierra nuestros religiosos', F. de Santa Inés, Filipinas, 1676), pero también en los que emplean tener ('La tierra del que representaron, que tenia recién perdida', P. Simón, Venezuela, 1627) o haber ('Si a Christo recién nacido, Angelo, o sus lastimosas penas, nos as referido', Corral, España, 1632). Teniendo esto en cuenta, no es difícil suponer una modificación morfosintáctica que hace que recién pase de afectar al participio a afectar al tiempo compuesto en su totalidad (esto es, de Ha recién nacido a Ha nacido recién), dando origen de este modo a los usos autónomos de este elemento, tal habituales hoy en el español americano.

Así pues, se puede decir que los empleos innovadores americanos son, efectivamente, una ampliación de las posibilidades sintácticas del recién español, pero no de las actuales (recién seguido exclusivamente de participio), sino de las existentes en el siglo XVII en la Península, donde este elemento se acompaña de otros adjetivos, de diferentes sustantivos o se introduce en un tiempo compuesto; surgen, de este modo, nuevas preguntas sobre la historia de recién que es necesario responder: no sólo cuándo y por qué se origina la ampliación de posibilidades sintácticas ya indicada en América, sino también cuándo y por qué se produce la reducción de contextos de uso en el caso del español peninsular. Todo ello no hace sino acentuar, evidentemente, la necesidad de llevar a cabo más estudios sobre la evolución morfosintáctica y significativa de este elemento, cuyo desarrollo diacrónico — no sólo en América, sino también en España- resulta por el momento prácticamente desconocido.

${ }^{26}$ Dado que algunos ejemplos no tienen una fecha concreta, sino que abarcan un intervalo de tiempo, se ha optado por englobarlos en aquella de las divisiones propuestas con la que cronológicamente coincide en mayor grado; de este modo, un ejemplo como el número 1, datado entre 1822 y 1838, se ha incluido en el periodo 1801 - 1835, por ser éste el de mayor coincidencia cronológica con él. 
Parece evidente, a la luz de estos datos, que los usos innovadores de recién adquieren más importancia paulatinamente a lo largo del siglo XIX, lo que se refleja en el constante aumento de su porcentaje de uso: dejando aparte el periodo 1801-1830 —-donde lo escaso de los datos resta validez a los resultados porcentuales-, el corpus ofrece un 46' $15 \%$ de usos no participiales entre 1836 y 1870 que asciende hasta el $65{ }^{\prime} 55 \%$ en la última parte del siglo, progresión que tiene su contracara en el descenso de los porcentajes de recién + participio, que pasan de un 53'85\% a un $34^{\prime} 44 \%$ en el tercio final del siglo.

Así pues, y de acuerdo con los datos expuestos en estas líneas, se puede decir que el español rioplatense experimenta un proceso de cambio en la utilización de recién a lo largo de su historia, de manera que, mientras que en los siglos XVII y XVIII su empleo se produce únicamente seguido de participio - $-\mathrm{y}$ coincide, por tanto, con el que actualmente se registra en España-, a lo largo del siglo XIX se van a desarrollar unos usos —en principio- innovadores que van a dar lugar a la situación actual, caracterizada por la aparición de este elemento en otros contextos sintácticos; en concreto, los primeros ejemplos de esta peculiaridad en el Río de la Plata, registrados en los poemas de Juan Cruz Varela, se datan en la Argentina en 1823 (ejemplos 6 y 7):

6. Estas riberas recién dejaba el implacable Yarbas (Argentina, 1823)

7. De su lado recién me apartaré (Argentina, 1823)

Por lo que se refiere a los distintos usos innovadores de recién en esta época, los datos del corpus demuestran que el siglo XIX ofrece una situación muy parecida a la actual, dado que están ya presentes las dos posibilidades de aparición que muestra hoy el español rioplatense ${ }^{27}$, esto es, su empleo como elemento autónomo y como introductor de un complemento temporal ${ }^{28}$; es de destacar a este respecto, con todo, las diferencias porcentuales que se registran entre los dos usos (tabla 3):

${ }^{27}$ Esta semejanza con la situación actual se produce, por supuesto, en cuanto a las posibilidades de aparición de este elemento; sin embargo, la falta de estudios sobre recién en la sincronía presente hace que se ignore por el momento si sus porcentajes de uso coinciden con los que ofrece hoy en día el español de la región, algo de notable interés para comprender mejor la historia de estos empleos innovadores en el área.

28 Junto a los complementos de tiempo, que constituyen la práctica totalidad, se localizan también dos casos de complementos de lugar, en concreto en obras gauchescas de la segunda mitad del siglo XIX:

A. Como a pleito lo siguió hasta Salta, pues allí recién Tristán sujetó (H. Ascasubi; Argentina, 1872)

B. Ensartado lo llevé y allá recién lo largué cuando ya lo sentí muerto (J. Hernández; Argentina, 1879) 
TABLA 3

Contexto de aparición de recién no participial (Siglo XIX)

\begin{tabular}{|l|c|c|c|}
\hline \multicolumn{1}{|c|}{ Contexto } & Casos & Porcentaje & Primer Ejemplo \\
\hline - Autónomo & 83 & $75^{\prime} 45 \%$ & 1823 \\
\hline - Con complemento & 27 & $24^{\prime} 54 \%$ & 1844 \\
\hline TOTAL & 110 & $100 \%$ & - \\
\hline
\end{tabular}

Se hace evidente, por tanto, la clara preferencia que existe en el español rioplatense decimonónico por el uso de recién como elemento autónomo, que alcanza un $75,45 \%$ de los usos innovadores frente a los 27 ejemplos -esto es, el 24'54\% restante- de su empleo como introductor de complemento ${ }^{29}$; en relación con esto, hay que indicar también que se registra una leve antelación cronológica en el más abundante de estos contextos de aparición, si bien es probable que este hecho se deba al azar y no sea significativo.

Por otro lado, y en contraste con el aumento continuado de los usos innovadores a lo largo del siglo XIX, en el caso de los diferentes contextos de aparición no se descubre ninguna variación porcentual de importancia: dejando una vez más de lado el primer tercio de siglo por su escasez de datos - y en el que aparece exclusivamente el recién autónomo-, el periodo 1836-1870 ofrece un 69'38\% de casos para esta posibilidad y un 30'61\% para recién + complemento, mientras que en la última parte del siglo los porcentajes son del 76'27\% y del 23'72\% respectivamente; oscilaciones, por tanto, de menos de un siete por ciento que muy probablemente se puedan achacar al corpus y no tanto a un cambio en las tendencias de uso de este elemento en la centuria señalada.

4. Así pues, del análisis llevado a cabo a lo largo de estas páginas se puede extraer una serie de conclusiones de cierto interés para la historia del recién rioplatense, las más importantes de las cuales se sintetizan a continuación.

En primer lugar, los datos parecen poner de manifiesto que el siglo XIX constituye un momento de gran importancia en la historia de los usos americanos de este elemento, ya que es precisamente en esta centuria cuando se registran por primera vez ejemplos de este tipo: en efecto, mientras los materiales de los siglos XVII y XVIII sólo ofrecen casos de recién + participio, en el siglo siguiente estas construcciones alternan con aquellas en las que este elemento aparece o bien de forma autónoma o bien acompañado de un complemento de

${ }^{29}$ Las apariciones más antiguas del recién autónomo, datadas en 1823, corresponden a los ejemplos 6 y 7 citados anteriormente; en el caso de recién + complemento, su primera atestiguación en el corpus es la siguiente:

C. Oyen hoy un chiste y mañana recién ríen de él (J. B. Alberdi; Argentina, 1844-51) 
carácter temporal; a este respecto, se debe decir, además, que la presencia de estos usos innovadores en este siglo no es algo ocasional o puramente anecdótico, sino que alcanza unos porcentajes muy notables, en concreto de un 55 ' $27 \%$ del total.

En relación con lo anterior, y como complemento de los datos anteriormente señalados, se hace necesario indicar que los datos del corpus apuntan - más allá del ya mencionado origen del uso americano de recién en el siglo XIX-, a una progresión en el uso de estas innovaciones conforme avanza la centuria, algo que parece descubrirse en el incremento de los porcentajes de estos empleos novedosos en los diferentes periodos cronológicos en que se ha dividido el siglo: así, frente al 46'15\% del corte 1836-1870, en su último tercio estos usos alcanzan ya un $65^{\prime} 55 \%$ del total de casos de recién, lo que —en principio- podría avalar la idea de una generalización de estos empleos en el español decimonónico del Río de la Plata.

Por otro lado, este análisis permite constatar la existencia ya en el siglo XIX de las dos estructuras que hoy se consideran propias de América respecto al uso de recién, esto es, su aparición como elemento autónomo y su empleo como introductor de complementos preferentemente de tipo temporal: de acuerdo con el corpus aquí analizado, el primero de ellos aparece de forma más frecuente, en el $75,45 \%$ de los casos, mientras que el segundo - esto es, recién entonces- presenta unos porcentajes más bajos, prácticamente el $25 \%$ del total; una relación, por tanto, de tres a uno a favor del uso autónomo, en una proporción que no parece experimentar oscilaciones en toda la época atendida en este estudio.

A la luz de estos datos, pues, son varias las cuestiones que parecen plantearse a lo investigadores: en primer lugar, y teniendo en cuenta la situación de recién en el español peninsular del siglo XVII, resulta difícil pensar que estos usos denominados innovadores son desconocidos en el español rioplatense antes del siglo XIX y aparecen por vez primera en este momento, por lo que se hace necesario consultar nuevos corpora del periodo colonial para buscar ejemplos que adelanten las primeras dataciones de estos usos en el Río de la Plata y que arrojen, así mismo, indicios sobre su origen y su difusión en el español de la región; por otro lado, y una vez se tenga relativa certeza sobre el momento de su aparición, se deberá también explicar el porqué, si no de su nacimiento, al menos de su generalización en la lengua escrita de esta zona en las primeras décadas del siglo XIX, y a este respecto es muy probable que fenómenos como la extensión de las ideas románticas o la misma independencia de las repúblicas del Plata - con las transformaciones políticas y culturales que conllevan- no sean ajenos al proceso de incorporación de este americanismo morfosintáctico a la lengua escrita. 
Son muchas, por tanto, las cuestiones que aún quedan por estudiar acerca de la historia de recién y de sus usos, muy especialmente - aunque no sóloen lo que se refiere a las variedades americanas de la lengua; a este respecto, y en relación con el Río de la Plata, el presente trabajo no tenía otro propósito que aportar algunos datos de interés para la redacción de esa historia, pero es del todo evidente que son aún necesarios nuevos trabajos que complementen lo esbozado en esta primera aproximación: tal vez cuando se cuente con ellos, recién entonces, se pueda describir con cierta profundidad el desarrollo de un aspecto tan peculiar y característico del español de esta región como desconocido desde un punto de vista diacrónico. 